\title{
PERSEPSI WISATAWAN TERHADAP KUALITAS PELAYANAN STARBUCKS COFFEE DI BANDARA NGURAH RAI BALI
}

Putri Swastika P a,1, I Gst. Agung Oka Mahaganggaa, 2

1 sauvastikhan@gmail.com, 2 ragalanka@gmail.com

a Program Studi S1 Destinasi Pariwisata,Fakultas Pariwisata,Universitas Udayana, Jl. Dr. R. Goris, Denpasar, Bali 80232 Indonesia

\section{ABSTRACT}

Consistency of service and product quality continue to be pursued by Starbucks Coffee as one of popular tenants at Drop Off Zone I Gusti Ngurah Rai Bali Airport, to provide a good service for passengers, especially the tourists in order to obtain a positive impression during their presence at Bali Airport. However, there has been no absolute survey of tourist's feedback, which is required to monitor and improve the performance of the team. The research aims to determine tourists' perception toward the product and service quality of Starbucks Bali Airport, with the result that management will acquire useful information.

The data sources in this study are primary and secondary data, which are collected through literature study, observation, interview, and questionnaires. The sample is selected using accidental sampling technique, while the quantitative data from questionnaires are analyzed using a Likert scale and described qualitatively.

The result of the study shows that perception of tourists toward the quality service of Starbucks Coffee Bali Airport obtains the total score of 417 which is classified as 'good' category. Dimension of reliability is the most preferential aspect with acquisition attitude score of 4.27 comes in the 'excellent' category; otherwise the worst aspects are the dimensions of responsiveness with attitude score result of 4.14 and classified in 'good' categories only. Speed of service comes in the major variable with score of 4.52 which can be categorized as 'excellent' otherwise, the quality of free Wifi obtained the lowest score of 3.67, where 8 tourists rate 'poor' and 4 tourists mark 'terrible' to this variable.

Keywords : tourists, perception, service quality, Starbucks Coffee. 


\section{PENDAHULUAN}

\subsection{Latar Belakang}

Keberadaan Starbucks Coffee Bandara Ngurah Rai Bali, yang merupakan 'pintu gerbang' sebuah destinasi pariwisata internasional menjadikannya sebagai salah satu dari sejumlah gerai Starbucks Indonesia dengan penjualan tertinggi. Konsistensi kualitas pelayanan terus diupayakan manajemen Starbucks Bandara Ngurah Rai karena selain kopi, pelayanan juga menjadi produk utama yang ditawarkan (core product).

Survey seputar kualitas pelayanan dibutuhkan untuk memantau dan meningkatkan kinerja tim, mengingat jumlah kunjungan yang terus mengalami peningkatan serta karakteristik pelanggan yang sangat variatif. Oleh karena itu, penelitian tentang persepsi wisatawan terhadap kualitas pelayanan dirasa efektif dalam menggali feedback nyata wisatawan sebagai pelanggan terhadap kualitas pelayanan Starbucks Coffee di Bandara I Gusti Ngurah Rai Bali.

\subsection{Rumusan Masalah}

Permasalahan yang dikaji dalam tulisan ini adalah Bagaimana Persepsi Wisatawan terhadap Kualitas Pelayanan Starbucks Coffee di Bandara Ngurah Rai Bali?

\subsection{Tujuan Penelitian}

Melalui penelitian ini akan diketahui skor dan kategori kualitas pelayanan Starbucks berdasarkan persepsi wisatawan sehingga diharapkan dapat memberi informasi yang diperlukan manajemen dalam mengevaluasi kinerja staff selama operasional berlangsung.

\section{KEPUSTAKAAN}

\subsection{Batasan Pengertian Persepsi}

Persepsi menurut Schacter (2011) berarti tindakan mengenali, menyusun, dan menafsirkan informasi sensoris guna memberi gambaran dan pemahaman tentang lingkungan. Menurut Sunaryo (2004), melalui persepsi individu dapat menyadari dan memahami keadaan lingkungan disekitarnya. Persepsi diawali dengan proses penginderaan, yaitu diterimanya stimulus oleh alat indra, kemudian individu menaruh perhatian terhadap objek stimulus tersebut, selanjutnya diteruskan ke otak, sehingga munculah 'persepsi' sebagai proses akhir.

\subsection{Batasan Pengertian Kualitas}

Kualitas ialah keseluruhan sifat suatu pelayanan atau produk yang mempengaruhi kemampuannya dalam memuaskan kebutuhan pelanggan (Kotler, 2003). Suatu barang dan jasa akan dinilai berkualitas atau bermutu jika mampu melampaui harapan pelanggan.

\subsection{Batasan Pengertian Pelayanan}

Barata (2004) mendefinisikan pelayanan sebagai suatu urutan aktivitas yang terjadi dalam interaksi langsung antara seseorang (pegawai) dengan orang lain (pelanggan) secara fisik dan menimbulkan rasa puas terhadap pelanggan tersebut.

\subsection{Tinjauan Kualitas Pelayanan}

Pelayanan yang berkualitas adalah yang dilakukan secara 'maksimal' dan telah memenuhi standar yang harus dicapai oleh perusahaan.

Ada lima dimensi yang menjadi pertimbangan konsumen dalam melakukan penilaian terhadap kualitas pelayanan (Service Quality). Menurut Parasuraman dkk (1985) dalam Khosrow (2002) kelima dimensi tersebut adalah:

a) Tangible atau bukti langsung, antara lain kondisi fisik fasilitas, perlengkapan, dan penampilan karyawan.

b) Empathy atau kepedulian yaitu, kemudahan menjalin hubungan baik, memberi perhatian dan memahami kebutuhan pelanggan.

c) Reliability atau kehandalan, meliputi kemampuan memberi pelayanan yang dijanjikan dengan segera, tepat, akurat, dan memuaskan.

d) Responsiveness atau daya tanggap, merupakan kesiapan dan daya tanggap para staff untuk membantu pelanggan.

e) Assurance atau jaminan, adalah pengetahuan, keterampilan, kesopanan, dan sifat 'dapat diandalkan' yang dimiliki staff atau karyawan. 


\section{METODE PENELITIAN}

\subsection{Lokasi Penelitian}

Penelitian ini dilaksanakan di Starbucks Coffee Drop Off Zone Bandara Ngurah Rai Bali dengan pertimbangan angka sales yang tinggi serta lokasi yang strategis, sehingga banyak dijumpai wisatawan sedang beraktivitas makan dan minum disana.

\subsection{Ruang Lingkup Penelitian}

Batasan permasalahan dalam tulisan ini yaitu persepsi wisatawan terhadap kualitas pelayanan Starbucks Coffee di Drop Off Zone Bandara I Gusti Ngurah Rai Bali ditinjau dari 5 dimensi SERVQUAL menurut Parasuraman dkk (1985) dalam Khosrow (2002) yaitu Tangible, Empathy, Responsiveness, Responsibility, dan Assurance..

\subsection{Jenis dan Sumber Data}

Jenis data penunjang penelitian ini adalah data kualitatif berupa catatan hasil wawancara kepada manajemen Starbucks, catatan hasil observasi selama dilakukan penelitian di lokasi, serta data yang diperoleh dari beberapa literatur pada Bab Studi Kepustakaan Serta data kuantitatif berupa jumlah kunjungan wisatawan Australia di Bali. Miles and Huberman (1994), dalam Natalia (2010) mengatakan "qualitative data are well suited for locating the meanings people place on the events, processes, and structures of their lives: their perceptions, assumptions, prejudgments, presuppositions ... and to connect these meanings to the social world around them."

Selain itu data kuantitatif berupa jawaban kuesioner yang dianalisis menggunakan skala Likert, dan data numeric lain yang dibutuhkan sebagai penunjang dan didapat selama penelitian berlangsung. Menurut Sugiyono (2010) data kuantitatif merupakan data yang berfungsi menentukan besaran atau jumlah objek penelitian, yang bisa diolah menggunakan perhitungan matematika.

Sumber data dalam penelitian ini yaitu data primer dan data sekunder.

\subsection{Teknik Penentuan Informan}

Sampel dipilih menggunakan teknik accidental sampling, diambil 100 orang wisatawan pelanggan Starbucks yang sedang melakukan aktivitas makan dan minum pada saat penelitian berlangsung untuk mengisi kuesioner. Pengambilan 100 orang responden ini juga mengacu pada ADT (Actual Daily Transaction) atau jumlah transaksi yang terjadi dalam satu hari operasional Starbucks Airport Bali.

Menurut Arikunto (1998), apabila subjeknya kurang dari 100 lebih baik diambil semua sehingga penelitiannya merupakan penelitian populasi, namun apabila penelitiannya besar dapat diambil antara 10$15 \%$ atau $20-25 \%$ atau lebih tergantung dari kemampuan peneliti, luas wilayah pengamatan, dan besar kecil resiko yang ditanggung peneliti.

\subsection{Teknik Pengumpulan Data}

a) Observasi dengan pengamatan secara langsung kondisi di Starbucks Bandara Ngurah Rai dan membuat catatan mengenai situasi saat itu. "Partisipant Observation enables researchers to become aware of how the participants construct and describe their world" Jennings (2010).

b) Wawancara dengan mengajukan sejumlah pertanyaan kepada manajemen Starbucks di Bandara Ngurah Rai yang dapat memberi informasi penting untuk menunjang penelitian. teknik wawancara dianggap lebih fleksibel karena pewawancara dapat mengadaptasi situasi dan respon dari informan sehingga dapat mengembangkan pertanyaan-pertanyaan demi memperoleh informasi yang dibutuhkan (Goeldner dan Ritchie, 2009).

c) Kuesioner dengan mengajukan beberapa butir pernyataan mengenai kualitas pelayanan Starbucks di Bandara Ngurah Rai dan meminta responden untuk memberi tanggapannya. "The main purpose of a questionnaire is to provide a vehicle for obtaining accurate information from $a$ respondent, whether the questionnaire itself is very short or long, comprised of questions that are open-ended or closed and implemented by direct or distributed means." Brotherton (2008).

d) Studi kepustakaan dengan mengkaji berbagai referensi, buku, internet, dan literatur yang berkaitan dengan permasalahan sehingga dapat dijadikan acuan dalam pembahasan penelitian ini. 
Agar suatu penelitian memiliki dasar yang kokoh, teori-teori dan konsep pada umumnya dapat ditemukan dalam sumber acuan umum seperti kepustakaan yang berupa buku-buku teks, ensiklopedia, monograph, atau sejenisnya (Suryabrata, 1987).

\subsection{Teknik Analisis Data}

Data dalam penelitian ini dianalisis menggunakan metode deskriptif kuantitatif. Data numerik yang diperoleh akan diuraikan atau dideskripsikan dalam bentuk narasi untuk memperoleh gambaran dan pemahaman yang jelas mengenai persepsi wisatawan terhadap kualitas pelayanan Starbucks di Bandara Ngurah Rai.

Untuk menganalisis persepsi wisatawan, data hasil kuesioner diukur menggunakan Skala Likert dengan mengajukan dua puluh butir pernyataan bersifat positif yang masing-masing diberikan lima alternatif jawaban dengan bobot yang berbeda. Wisatawan yang menjadi responden diminta memilih salah satu jawaban yang mewakili tanggapan mereka terhadap keberadaan Starbucks di Bandara Ngurah Rai.

a) Skor lima diberikan untuk penilaian sangat baik atau Excellent.

b) Skor empat diberikan untuk penilaian baik atau Good.

c) Skor tiga diberikan untuk penilaian cukup atau Average.

d) Skor dua diberikan untuk buruk atau Poor.

e) Skor satu untuk penilaian sangat buruk atau Terrible.

Skor akhir didapatkan dengan menjumlahkan angka tiap-tiap jawaban. Untuk mengetahui intensitas sikap wisatawan, terlebih dahulu perlu dicari rentang nilainya (interval) dimana dalam menemukan interval, sesuai dengan kategori yang diberikan yaitu satu (1) untuk nilai terendah dan lima (5) untuk nilai tertinggi maka digunakan rumus sebagai berikut:

$$
\begin{aligned}
\frac{\text { Skor tertinggi }- \text { skor terendah }}{\text { jumlah kelas } \frac{5-1}{5}}=0,80
\end{aligned}
$$

Berdasarkan rumus interval tersebut, setiap kategori memiliki rentang nilai sebesar
0,80 maka sikap responden terhadap masingmasing pernyataan yang diajukan dapat dianalisis dengan kategori sikap wisatawan yang telah disusun sebagai berikut:

$$
\frac{\text { jumlah skor } \times \text { skor }}{\text { jumlah responden }}=\text { nilai sikap }
$$

Tabel 1. Skala Sikap

\begin{tabular}{|c|c|c|c|}
\hline No. & $\begin{array}{c}\text { Kriteria } \\
\text { Penilaian }\end{array}$ & Skor & Kategori \\
\hline 1. & $\begin{array}{c}\text { Excellent atau } \\
\text { 'sangat baik' }\end{array}$ & 5 & $4,24-5,04$ \\
\hline 2. & $\begin{array}{c}\text { Good atau } \\
\text { 'baik' }\end{array}$ & 4 & $3,43-4,23$ \\
\hline 3. & $\begin{array}{c}\text { Average atau } \\
\text { 'cukup' }\end{array}$ & 3 & $2,62-3,42$ \\
\hline 4. & $\begin{array}{c}\text { Poor atau } \\
\text { 'buruk' }\end{array}$ & 2 & $1,81-2,61$ \\
\hline 5. & $\begin{array}{c}\text { Terrible atau } \\
\text { 'sangat } \\
\text { buruk' }\end{array}$ & 1 & $1,00-1,80$ \\
\hline
\end{tabular}

Sumber : Hasil modifikasi Skala Likert (Arikunto, 1998)

\section{HASIL DAN PEMBAHASAN}

4.1 Gambaran Umum Starbucks Bandara Ngurah Rai

Drop Off Zone di Bandara Ngurah Rai Bali dirasa cukup strategis oleh manajemen PT. Sari Coffee untuk mendirikan gerai ke-67 Starbucks Coffee Indonesia, dimana titik ini dilalui oleh jalur keberangkatan dan kedatangan domestik serta letaknya yang berada di luar terminal sehingga tidak hanya penumpang pesawat saja yang dapat berkunjung ke Starbucks.

Starbucks menawarkan kopi terbaik di dunia, yang ditanam, dipelihara, dikelola, dan disajikan oleh orang-orang terpilih pula maka, staff atau yang disebut partner atau Barista adalah jantung dari segalanya (the heart of Starbucks experience).

Partner diseleksi berdasarkan beberapa kualifikasi seperti pendidikan, pengalaman organisasi, penampilan, kemampuan komunikasi dan bahasa, wawasan, serta passion atau semangat kerja. Selama masa kerjanya, partner baru yang disebut Green Bean akan mendapat kesempatan untuk mengikuti coffee class dalam rangka memperdalam ilmu dan keterampilannya sebagai Barista hingga memperoleh sertifikat Coffee Master dan berhak mengenakan 
celemek hitam atau Black Apron. Setelah itu Green Bean yang sudah matang sebagai Barista nantinya juga diikut sertakan dalam kompetisi kelas dunia seperti Latte Art Competition dan Coffee Ambassador.

Orang-orang terpilih inilah yang dipercaya menjadi icon pencitraan Starbucks yang dituntut agar selalu memberikan pelayanan kelas dunia bagi coffee lovers atau pelanggan.

\subsection{Penerapan Pelayanan Prima di} Starbucks Bandara Ngurah Rai

Pelayanan prima atau service excellence di Starbucks Coffee dikenal dengan istilah World Class Service. Penerapan pelayanan prima tidak hanya ditujukan kepada pelanggan eksternal namun juga orang-orang yang terlibat dalam perusahaan. Karena dengan membudayakan pelayanan prima di lingkungan internal merupakan langkah awal untuk mencapai keberhasilan dalam penerapan pelayanan prima bagi pelanggan eksternal.

Berdasarkan wawancara dengan Bapak Budi (Store Manager). ekspektasi manajemen akan hasil penelitian persepsi wisatawan terhadap kualitas pelayanan Starbucks Coffee di Bandara I Gusti Ngurah Rai Bali adalah memperoleh skor sikap dalam rentang 4,245,04 atau kategori 'sangat baik' di setiap variabel (nilai sempurna). Hal ini didasarkan pada implementasi visi dan misi perusahaan yang menuntut kesempurnaan pada setiap aspek dalam melayani pelanggan (put the customer first), dan dalam menghadapi persaingan. Unsur lain yang mendorong peningkatan kualitas pelayanan adalah kenaikan sales (penjualan) dari tahun 2014 dan tahun 2015.

\subsection{Karakteristik Pelanggan}

Salah satu upaya Starbucks dalam pencapaian World Class Service atau kualitas pelayanan prima, antara lain dengan mendalami karakteristik pelanggan yang beragam, sehingga Barista mampu memahami sekaligus memenuhi permintaan wisatawan sebagai pelanggan. Ada beberapa karakteristik pelanggan yang wajib dipelajari oleh Barista, sesuai keterangan Store Manager Starbucks Bandara Ngurah Rai yang tertuang dalam kitab perusahaan Starbucks Resource Manual adalah sebagai berikut:

a. New Customer (pelanggan baru) dengan ciri-ciri terlihat bingung ketika memasuki area kafe, tampak kesulitan menelaah menu board dan memutuskan pesanan. Menghadapi pelanggan jenis ini, Barista harus sigap mengarahkan pelanggan untuk mencoba minuman dan makanan favorit serta membimbing pelanggan dengan penuh perhatian agar memperoleh makanan atau minuman yang benar-benar sesuai dengan selera. Keramahan dan ketelatenan Barista dalam melayani pelanggan baru dapat meninggalkan kesan positif sehingga New Customer tertarik untuk berkunjung kembali dan menjadi pelanggan tetap (Regular Customer).

b. Regular Customer (pelanggan tetap), ciricirinya antara lain memiliki kartu pembayaran Starbucks dan sudah hafal produk minuman maupun makanan yang diinginkan. Pelanggan tetap juga seringkali menanyakan promo yang sedang berjalan.

c. Customer in hurry (pelanggan terburuburu) biasanya tidak menerima tawaran promosi maupun additional ingredients, serta memesan dengan cepat agar transaksi segera terselesaikan.

d. Retail Customer memasuki area kafe langsung menuju merchandise bay untuk melihat-lihat dan bertanya mengenai whole beans atau merchandise yang ditawarkan. Pelanggan seperti ini sebagian besar merupakan traveler dan wisatawan yang mengaku sebagai kolektor merchandise Starbucks maupun membeli untuk dijadikan souvenir yang dibawa pulang ke daerah asalnya.

e. Unsatisfied Customer (pelanggan tidak puas) dapat diperhatikan pada raut muka kecewa atau tidak senang. Sejumlah hal dapat menyebabkan pelanggan merasa tidak puas seperti kesalah pahaman antara minuman yang diinginkan dengan minuman yang disajikan dan sebagainya. Barista dituntut memberi perhatian penuh terhadap pelanggan ini, membantu menyelesaikan masalah dengan penerapan say 'yes' philosophy dan memastikan 
pelanggan tersebut memasang raut muka senang ketika meninggalkan kafe.

Pada dasarnya wisatawan pengunjung Starbucks Bandara Ngurah Rai dapat digolongkan pada semua karakteristik pelanggan Starbucks yang telah dipaparkan tersebut sesuai dengan kondisinya. Namun observasi yang dilaksanakan selama penelitian berlangsung, menunjukkan wisatawan pengunjung Starbucks Bandara Ngurah Rai cenderung mengarah pada kategori Regular Customer dan Retail Customer. Dikatakan regular sekaligus retail customer karena wisatawan tersebut sudah sering mengunjungi gerai Starbucks dimanapun dan sangat mengenal produknya, serta mengaku mengkoleksi merchandise Starbucks seperti cangkir atau mug dengan corak berciri khas daerah-daerah gerai Starbucks tersebut.

\subsection{Persepsi Wisatawan Terhadap Kualitas Pelayanan Starbucks Bandara Ngurah Rai Bali}

Upaya manajemen untuk selalu memberikan pelayanan prima terhadap wisatawan sebagai pelanggan pada akhirnya dapat diukur melalui penelitian persepsi wisatawan terhadap kualitas pelayanan Starbucks Bandara Ngurah Rai. Hasil penelitian menunjukkan bahwa kualitas pelayanan Starbucks Bandara Ngurah Rai menurut persepsi wisatawan dapat dikategorikan 'baik'.

Sebelumnya telah dijabarkan mengenai penerapan konsep World Class Service di Starbucks Bandara Ngurah Rai. Akan tetapi hasil penelitian menunjukkan ketidak sesuaian ekspektasi manajemen dengan persepsi wisatawan, dimana manajemen berharap memperoleh predikat 'sangat baik' (skor sikap dalam rentang nilai 4.24-5.04) dalam segala aspek kualitas pelayanan yang diberikan, mengingat service excellence yang selalu diterapkan di gerainya. Pada kenyataannya kualitas pelayanan Starbucks Bandara Ngurah Rai hanya memperoleh predikat 'baik' (skor sikap dalam rentang nilai 3.43-4.23) berdasarkan pengalaman wisatawan sebagai pelanggan (tabel 7).

Tabel 2. Persepsi Wisatawan Terhadap Dimensi Tangible

\begin{tabular}{|c|c|c|c|c|c|c|c|c|c|c|}
\hline No. & Variabel/Indikator & $\begin{array}{c}\text { Sangat } \\
\text { Baik }\end{array}$ & Baik & Cukup & Buruk & $\begin{array}{l}\text { Sangat } \\
\text { Buruk }\end{array}$ & Total & $\begin{array}{l}\text { Total } \\
\text { Skor }\end{array}$ & $\begin{array}{c}\text { Skor } \\
\text { Sikap }\end{array}$ & $\begin{array}{l}\text { Kriteria } \\
\text { Persepsi }\end{array}$ \\
\hline 1. & $\begin{array}{c}\text { Lokasi mudah } \\
\text { dijangkau }\end{array}$ & 38 & 49 & 13 & - & - & 100 & 425 & 4.25 & Baik \\
\hline 2. & Penampilan Barista & 36 & 58 & 6 & - & - & 100 & 430 & 4.30 & $\begin{array}{c}\text { Sangat } \\
\text { Baik }\end{array}$ \\
\hline 3. & $\begin{array}{l}\text { Variasi menu dan } \\
\text { produk }\end{array}$ & 26 & 48 & 23 & 3 & - & 100 & 397 & 3.97 & Baik \\
\hline 4. & Kebersihan area kafe & 31 & 47 & 18 & 4 & - & 100 & 405 & 4.05 & Baik \\
\hline & \multicolumn{8}{|c|}{ Rata-rata Variabel } & 4.14 & Baik \\
\hline
\end{tabular}

Sumber: diolah dari penelitian 2015

Untuk mengukur persepsi wisatawan terhadap kualitas pelayanan dalam dimensi Tangible, Indikator yang digunakan antara lain lokasi atau keberadaan, penampilan Barista, variasi menu dan produk yang ditawarkan, serta kebersihan dan kerapihan area kafe.
Berdasarkan tabel diatas, kualitas pelayanan Starbucks Bandara Ngurah Rai dalam

dimensi ini dapat dikategorikan 'baik' dengan perolehan total skor sikap 4.14. 
Tabel 3. Persepsi Wisatawan Terhadap Dimensi Empathy

\begin{tabular}{|c|c|c|c|c|c|c|c|c|c|c|}
\hline No. & Variabel/Indikator & $\begin{array}{c}\text { Sangat } \\
\text { Baik }\end{array}$ & Baik & Cukup & Buruk & $\begin{array}{l}\text { Sangat } \\
\text { Buruk }\end{array}$ & Total & $\begin{array}{l}\text { Total } \\
\text { Skor }\end{array}$ & $\begin{array}{l}\text { Skor } \\
\text { Sikap }\end{array}$ & $\begin{array}{l}\text { Kriteria } \\
\text { Persepsi }\end{array}$ \\
\hline 5. & Keramahan Barista & 45 & 49 & 6 & - & - & 100 & 439 & 4.39 & $\begin{array}{c}\text { Sangat } \\
\text { Baik }\end{array}$ \\
\hline 6. & $\begin{array}{c}\text { Pengetahuan Barista } \\
\text { tentang Kopi dan } \\
\text { Peralatannya }\end{array}$ & 23 & 59 & 17 & 1 & - & 100 & 404 & 4.04 & Baik \\
\hline 7. & Tingkat keamanan & 25 & 47 & 26 & 2 & - & 100 & 395 & 3.95 & Baik \\
\hline \multirow[t]{2}{*}{8.} & Suasana & 41 & 41 & 15 & 3 & - & 100 & 420 & 4.20 & Baik \\
\hline & \multicolumn{8}{|c|}{ Rata-rata Variabel } & 4.14 & Baik \\
\hline
\end{tabular}

Sumber: diolah dari penelitian 2015

Empathy adalah perwakilan emosi atau perasaan yang sama, dimana Barista dapat selalu memahami serta memberi yang terbaik yang diinginkan dan dibutuhkan oleh wisatawan sebagai pelanggan, sehingga wisatawan merasa diperhatikan dengan baik dan puas terhadap pelayanan yang diberikan.

Kualitas pelayanan Starbucks Bandara Ngurah Rai pada dimensi empathy dapat dikatakan 'baik' dengan total skor sikap 4.14.

Tabel 4. Persepsi Wisatawan Terhadap Dimensi Reliability

\begin{tabular}{|c|c|c|c|c|c|c|c|c|c|c|}
\hline No. & Variabel/Indikator & $\begin{array}{c}\text { Sangat } \\
\text { Baik }\end{array}$ & Baik & Cukup & Buruk & $\begin{array}{l}\text { Sangat } \\
\text { Buruk }\end{array}$ & Total & $\begin{array}{l}\text { Total } \\
\text { Skor }\end{array}$ & $\begin{array}{c}\text { Skor } \\
\text { Sikap }\end{array}$ & $\begin{array}{l}\text { Kriteria } \\
\text { Persepsi }\end{array}$ \\
\hline 9. & $\begin{array}{c}\text { Kemampuan Barista } \\
\text { dalam Menyajikan } \\
\text { Minuman }\end{array}$ & 40 & 49 & 11 & - & - & 100 & 429 & 4.29 & $\begin{array}{l}\text { Sangat } \\
\text { Baik }\end{array}$ \\
\hline 10. & Keakuratan Pesanan & 55 & 41 & 4 & - & - & 100 & 451 & 4.51 & $\begin{array}{c}\text { Sangat } \\
\text { Baik }\end{array}$ \\
\hline 11. & Rasa Minuman & 40 & 50 & 9 & 1 & - & 100 & 429 & 4.29 & $\begin{array}{c}\text { Sangat } \\
\text { Baik }\end{array}$ \\
\hline 12. & Rasa Makanan & 28 & 45 & 25 & 2 & - & 100 & 399 & 3.99 & Baik \\
\hline & \multicolumn{8}{|c|}{ Rata-rata Variabel } & 4.27 & $\begin{array}{c}\text { Sangat } \\
\text { Baik }\end{array}$ \\
\hline
\end{tabular}

Sumber: diolah dari penelitian 2015

Aspek reliability merupakan cermin kemampuan Barista Starbucks Bandara Ngurah Rai dalam melayani sesuai yang dijanjikan dengan tepat dan handal.

Berdasarkan hasil kuisioner, kualitas pelayanan Starbucks Bandara Ngurah Rai pada dimensi Reliability dapat dikategorikan 'sangat baik' dengan perolehan skor sikap 4.27. Akan tetapi terdapat beberapa orang wisatawan memberi penilaian buruk terhadap aspek rasa minuman dan rasa makanan, sehingga dibutuhkan upaya untuk memperbaiki kualitas makanan dan minuman. 
Vol. 4 No 2, 2016

Tabel 5. Persepsi Wisatawan Terhadap Dimensi Responsiveness

\begin{tabular}{|c|c|c|c|c|c|c|c|c|c|c|}
\hline No. & Variabel/Indikator & $\begin{array}{c}\text { Sangat } \\
\text { Baik }\end{array}$ & Baik & Cukup & Buruk & $\begin{array}{c}\text { Sangat } \\
\text { Buruk }\end{array}$ & Total & $\begin{array}{c}\text { Total } \\
\text { Skor }\end{array}$ & $\begin{array}{c}\text { Skor } \\
\text { Sikap }\end{array}$ & $\begin{array}{c}\text { Kriteria } \\
\text { Persepsi }\end{array}$ \\
\hline 13. & Kecepatan pelayanan & 58 & 36 & 6 & - & - & 100 & 452 & 4.52 & $\begin{array}{c}\text { Sangat } \\
\text { Baik }\end{array}$ \\
\hline 14. & $\begin{array}{c}\text { Performa Barista } \\
\text { (penguasaan job } \\
\text { description) }\end{array}$ & 42 & 51 & 7 & - & - & 100 & 435 & 4.35 & $\begin{array}{c}\text { Sangat } \\
\text { Baik }\end{array}$ \\
\hline 15. & Fasilitas free Wifi & 26 & 31 & 31 & 8 & 4 & 100 & 367 & 3.67 & Baik \\
\hline 16. & $\begin{array}{c}\text { Kemampuan Barista } \\
\text { dalam mengatasi } \\
\text { masalah }\end{array}$ & 24 & 54 & 22 & - & - & 100 & 402 & 4.02 & Baik \\
\hline
\end{tabular}

Sumber: diolah dari penelitian 2015

Barista dituntut mampu menyesuaikan diri dengan flow atau arus transaksi agar selalu bisa melayani wisatawan sebagai pelanggan dengan sigap dan tanggap. Berdasarkan hasil kuisioner, kualitas pelayanan dalam dimensi Responsiveness memperoleh skor sikap 4.14 yang masuk pada kategori 'baik'. Dalam dimensi ini juga terdapat variabel paling unggul yaitu pada indikator kecepatan pelayanan dengan skor sikap 4.52 sekaligus terdapat indikator paling lemah yaitu pada fasilitas Wifi dimana 4 orang wisatawan memberi penilaian 'sangat buruk' terhadap variabel ini.

Tabel 6. Persepsi Wisatawan Terhadap Dimensi Assurance

\begin{tabular}{|c|c|c|c|c|c|c|c|c|c|c|}
\hline No. & Variabel/Indikator & $\begin{array}{c}\text { Sangat } \\
\text { Baik }\end{array}$ & Baik & Cukup & Buruk & $\begin{array}{l}\text { Sangat } \\
\text { Buruk }\end{array}$ & Total & $\begin{array}{l}\text { Total } \\
\text { Skor }\end{array}$ & $\begin{array}{l}\text { Skor } \\
\text { Sikap }\end{array}$ & $\begin{array}{l}\text { Kriteria } \\
\text { Persepsi }\end{array}$ \\
\hline 17. & $\begin{array}{c}\text { Kesesuaian harga } \\
\text { dengan kualitas produk }\end{array}$ & 23 & 49 & 25 & 3 & - & 100 & 392 & 3.92 & Baik \\
\hline 18. & Tingkat kepuasan & 36 & 56 & 8 & - & - & 100 & 428 & 4.28 & $\begin{array}{l}\text { Sangat } \\
\text { Baik }\end{array}$ \\
\hline 19. & $\begin{array}{c}\text { Keseluruhan kualitas } \\
\text { jika dibandingkan } \\
\text { dengan Coffee shop lain }\end{array}$ & 39 & 48 & 12 & 1 & - & 100 & 425 & 4.25 & $\begin{array}{l}\text { Sangat } \\
\text { Baik }\end{array}$ \\
\hline 20. & $\begin{array}{l}\text { Kemungkinan untuk } \\
\text { kembali berkunjung dan } \\
\text { merekomendasikan }\end{array}$ & 38 & 47 & 13 & 1 & 1 & 100 & 420 & 4.20 & Baik \\
\hline & \multicolumn{8}{|c|}{ Rata-rata Variabel } & 4.16 & Baik \\
\hline
\end{tabular}

Sumber: diolah dari penelitian 2015

Assurance dapat didefinisikan sebagai dimensi yang berkaitan dengan kemampuan dan perilaku Barista dalam menumbuhkan keyakinan serta rasa percaya wisatawan terhadap perusahaan.
Berdasarkan hasil penelitian, kualitas pelayanan Starbucks Bandara Ngurah Rai pada dimensi Assurance memperoleh total skor sikap 4.16 sehingga dapat dikategorikan 'baik'.

\section{Tabel 7. Persepsi Wisatawan Terhadap Kualitas Pelayanan Starbucks di Bandara Ngurah Rai Bali}

\begin{tabular}{|c|c|c|c|c|c|}
\hline Dimensi & Tangibles & Empathy & Reliability & Responsiveness & Assurance \\
\hline $\begin{array}{c}\text { Rata-rata } \\
\text { Variabel }\end{array}$ & 4.14 & 4.14 & 4.27 & 4.14 & 4.16 \\
\hline $\begin{array}{c}\text { Rata-rata } \\
\text { Keseluruhan }\end{array}$ & \multicolumn{5}{|c|}{4.17} \\
\hline
\end{tabular}

Sumber: diolah dari penelitian 2015 
Pihak manajemen berpandangan bahwa persepsi sangat berpengaruh pada kepuasan wisatawan sebagai konsumen. Persepsi wisatawan terhadap kualitas pelayanan Starbucks Coffee di Bandara I Gusti Ngurah Rai Bali dapat dikategorikan 'baik' dengan perolehan total skor 4.17. Walaupun hanya terpaut angka 0.07 untuk dapat mencapai ekspektasi manajemen, hal ini dirasa cukup mengecewakan karena manajemen berkesimpulan bahwa penerapan service excellence atau World Class Service digerai mereka belum maksimal.

Terdapat sejumlah hal yang perlu diperbaiki terutama pada kualitas makanan dan fasilitas free Wifi yang memperoleh skor rendah, kesimpulannya bahwa aspek inilah yang menyebabkan persepsi wisatawan terhadap kualitas pelayanan Starbucks Coffee di Bandara I Gusti Ngurah Rai Bali belum memenuhi ekspektasi manajemen.

\section{SIMPULAN DAN SARAN 5.1 Simpulan}

Berdasarkan hasil penelitian, persepsi wisatawan terhadap kualitas pelayanan Starbucks Coffee di Bandara I Gusti Ngurah Rai Bali dapat dikategorikan 'baik' dengan perolehan total skor 4.17. Implementasi World Class Service di Starbucks Bandara Ngurah Rai belum maksimal dan tidak sesuai antara ekspektasi manajemen dengan hasil yang diperoleh.

Reliability (kehandalan) menjadi dimensi paling unggul dengan perolehan skor sikap 4.27 yang masuk pada kategori 'excellent' atau 'sangat baik', sedangkan

\section{DAFTAR PUSTAKA}

Arikunto, Suharsini. 1998. Prosedur Penelitian, Suatu Pendekatan Praktis. Jakarta : Rineka Cipta.

Barata, Atep Adya. 2004. Dasar-Dasar Pelayanan Prima. Jakarta : Elex Media Komputindo.

Brotherton, Bob. 2008. Researching Hospitality and Tourism. Sage Publications.

Goeldner, Charles R. dan Ritchie, J. R Goeldner., 2009. TOURISM: Principles, Practices and Philosophies, Eleventh Edition. New Jersey : John Wiley \& sons, Inc.

Jennings, Gayle. 2010. Tourism Research, Second Edition. New Jersey : John Wiley \& sons, Ltd.

Khosrow, Mehdi. 2002. Issues \& Trends of Information Technology Management In Contemporary Organizations. USA : Idea Publishing. responsiveness (daya tanggap) menjadi yang paling lemah dengan skor sikap 4.14 dan masuk pada kategori 'baik'. Kecepatan pelayanan dalam dimensi responsiveness dan keramahan Barista dalam dimensi empathy menjadi variabel unggul skor masing-masing 4.52 dan 4.39 yang dapat dikategorikan 'sangat baik'. Kualitas free Wifi memperoleh skor terendah yaitu 3.67 dimana 8 orang wisatawan memberi penilaian 'buruk' dan 4 orang wisatawan menilai 'sangat buruk' terhadap variabel ini.

\subsection{Saran}

Berdasarkan fenomena tersebut saran yang dapat direkomendasikan antara lain:

1.) Membangun kesadaran menjaga kebersihan area kafe termasuk back office.

2.) Pemeliharaan CCTV, briefing partner beserta security dan menyediakan sign board yang menghimbau pelanggan agar tetap memperhatikan barang bawaannya.

3.) Pengawasan terhadap konsistensi dalam memperhatikan self life produk sekaligus pemeliharaan mesin dan peralatan operasional lain demi menjaga kualitas rasa.

4.) Pelatihan secara continue untuk menyegarkan kembali dan menambah pengetahuan Barista tentang kopi dan peralatannya.

5.) Perlu disegerakan upaya perbaikan koneksi jaringan Wifi yang sangat dibutuhkan wisatawan guna mencari informasi berkaitan dengan aktivitas wisatanya serta pembekalan ilmu IT bagi Barista.

Kotler, Phillip. 2003. Marketing Management $11^{\text {th }}$ Edition. New Jersey : Prentice Hall Int'l.

Natalia, Saenko."Destination Image of Denmark and it's effects on the Russian Outbound Travel". Aalborg University Master Thesis, 2010.

Schacter, Daniel. 2011. Psychology. Worth Publishers.

Sugiyono. 2010. Memahami Penelitian Kualitatif. Bandung: Alfabeta

Sunaryo. 2004. Psikologi Untuk Keperawatan. Jakarta : EGC.

Suryabrata, Sumadi. 1987. Metodologi Penelitian. Jakarta : Rajawali. 